\title{
LESSONS FROM HISTORY
}

\section{Because It's There ... The Education of George Mallory}

\author{
Rishi Madhok, MD; Jay Lemery, MD; George W. Rodway, PhD, APRN \\ From Emergency Medicine, New York-Presbyterian Hospital (Dr Madhok); Emergency Medicine, New York-Presbyterian Hospital and Weill \\ Cornell Medical College (Dr Lemery); College of Nursing and School of Medicine, University of Utah (Dr Rodway).
}

\begin{abstract}
Initiative, creativity, and resolve represent both the pillars of the Wilderness Medical Society (WMS) and the story of George Mallory. His journey from humble beginnings to his rise to become one of history's most legendary mountaineers is a testament to the impact of great mentors as well as the development of Mallory as a mentor himself. In this light, the path of George Mallory in mountaineering and the role of WMS in wilderness medicine share a common theme. This essay is not only a tribute to George Mallory but also a testament to the importance of mentorship and the role of WMS in inspiring mentorship and education to future pioneers.
\end{abstract}

Key words: wilderness medicine, Mallory, mentorship, education, mountaineering

At the time when George Leigh Mallory (1886-1924) and his colleagues set out to challenge Everest, it remained the "Third Pole" of the world, with terrain never trod upon by humans-with an atmosphere "thinner" than any climber had experienced before. Mastering Everest would require ingenuity, innovation, physical and mental stamina, and what Mallory himself came to describe as a "loyalty to the expedition ... and of carrying through a task begun."1 However, these qualities and his conviction were not developed upon the icy slopes of Everest. Mallory had arrived at Everest armed with and enabled by them. The education of George Leigh Mallory-from his beginnings, his mentors, and his expeditions-was what drove him to ascend Everest and thus must be understood in order to grasp the impact of his legacy.

Mallory was the eldest son of a country rector and, even at young age, began displaying a restlessness that would later manifest itself in the pursuit of high mountains. As a boy, he, like most children, began to climb anything around him, most famously ascending the spire of his father's church. Described as a young man of "fine physique but very limited experience [as a climber]," Mallory was also an all-around athlete, excelling in both football (soccer) and rowing later in college. ${ }^{1}$ When he was 14 , he won a competitive mathematics scholarship to Winchester. He was then slated for the College House,

Corresponding author: Rishi Madhok, MD, Emergency Medicine, New York-Presbyterian Hospital, 525 E 68th Street, New York, NY 10065 (e-mail: rim7001@nyp.org). the oldest and most prestigious of the boarding houses at Winchester.

George Mallory's continued habit of climbing on drainpipes at Winchester caught the attention of his college tutor, R. L. Graham Irving, who would discover Mallory's latent possibilities. Irving, 10 years older than Mallory, was a member of the (British) Alpine Club, and an accomplished climber. Reportedly, Irving was seeking new climbing companions after his previous partner died in an alpine climbing accident. Most notably as a mentor, he eschewed formality in favor of "[getting] to know [his] students as individuals and teaching through mutual respect and trust." Thus, in the summer of 1904, Irving, Mallory, and another boy left on a 3-week climbing trip in the Alps. Thanks to Irving, they received a comprehensive introduction to alpine climbing-long days and demanding terrain, with attempted ascents of several peaks. They also obtained a harsh introduction to high altitude maladies when they were forced to retreat within approximately $200 \mathrm{~m}$ of the summit of Mount Velan due to acute mountain sickness. It was a mountain trip that set the stage for young Mallory, heralding the beginning of a climbing life. As Irving wrote, they had "thrill in their hearts ... It is impossible to make any who have never experienced it realize what thrill means ...."1

Over the next year Irving would form the Winchester College Ice Club. Mallory was hooked. He would practice his climbing techniques on the centuries-old architecture, climbing a gate tower 50 feet above the college courtyard. Mallory would success- 


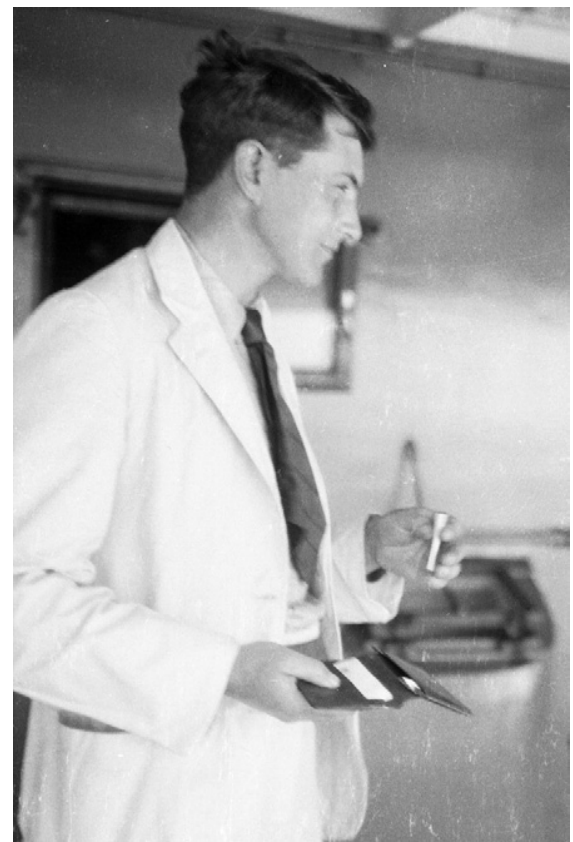

Figure 1. George Mallory in 1922. (Photo reprinted by permission of Anne Russell).

fully ascend Mont Blanc (the highest peak in continental Europe) and, under Irving's mentorship, his climbing skills flourished-becoming a mountain gymnast who would seemingly "walk up the as the moon." Mallory was the only climber to take part in all 3 of the pioneering British expeditions to Mount Everest, commencing with the reconnaissance journey in 1921 - and then 2 subsequent summit attempts on Everest in 1922 and 1924. Carrying the flag of exploration was a burden mixed with passion, with Mallory once reflecting, "I look back on tremendous efforts and exhaustion and dismal looking out of a tent door on to a dismal world of snow and vanishing hopesand yet, and yet, and yet there have been a good many things to see the other side."1 Mallory's expedition identified the first route possible to reach the summit of Everest. His expeditions led to greater scientific discovery as well as advancement of technology. The exploration of Everest led to the further development of climbing techniques and innovations such as supplementary oxygen for climbing at extreme altitude. Furthermore, Mallory and his teammates proved man could survive at an altitude exceeding $8000 \mathrm{~m}$, even without supplementary oxygen. Every one of their steps up Everest paced the way for 3 decades of mountaineers until Tenzing Norgay and Edmund Hillary successfully reached the summit on May 29th, 1953. Mallory's dedication and sacrifice lives on through the near 5000 successful attempts to reach the summit, as these mountaineers carry the spirit and inspiration of Mallory-and his passion for exploration.

There are few people in the world of outdoor adventure as iconic as George Mallory, and for a society predicated on the advancement of healthcare, research, and education related to wilderness medicine, these lessons from history offer a plan for the future viability of the Wilderness Medical Society (WMS). Mallory's body still lies on the slopes of Everest-discovered there in $1999,{ }^{2} 75$ years after his disappearance-but his legacy is in what he passed on to his own students and to the sport of mountaineering. Mallory chose to become a schoolmaster at Charterhouse, an English public school in Godalming, Surrey after his graduation from Cambridge University in 1910. He rejected the strict authoritarian methods of most British public schools of that era, preferring to teach, like his mentor Irving, through mutual respect and trust.

[Mallory] took an expansive view of the curriculum, recommending his pupils to read widely, talking to them about literature and politics, and setting essays on discursive subjects such as candor, popularity, and hypocrisy ... [many of his students] felt he was an inspirational teacher who had opened their eyes to far more than their formal subject matter. ${ }^{3}$

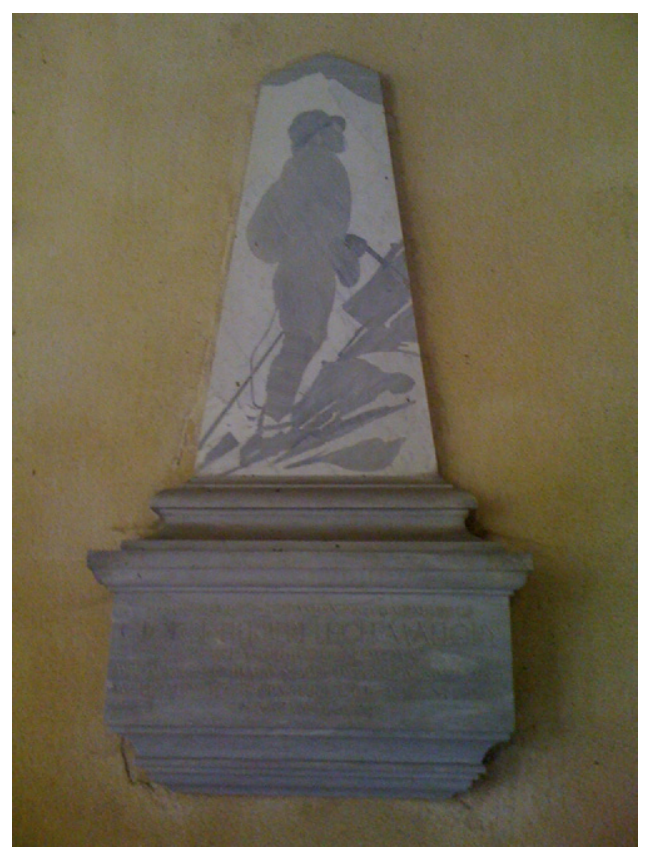

Figure 2. A memorial to George Mallory in the Winchester College Cloisters. Photo by Jay Lemery. 
The famous poet Robert Graves, a Charterhouse student from 1909 to 1914, indicated later in his life that Mallory was not only his best teacher at that institution, but also the first real friend he ever had. ${ }^{3}$

Mallory was an inspiration and pioneer not just on the mountain but also within a society very much different from our own. In Edwardian England, conformity and social consciousness were the rule. The motto of Winchester College had been enshrined since 1381: "Manners Makyth Man." This was hardly a mantra to inspire bold thinking and innovation. But in convention Mallory saw opportunity. As an instructor, Mallory identified the flaws of the "divisive and examination-obsessed" Britain. ${ }^{3}$ Breaking from tradition, Mallory sought greater collaboration between parents and teachers. He also sought to broaden his pupils' curriculum by exposing them to lessons previously unmentioned and to untaught cultures and societies. Finally, George Mallory promoted self-exploration of interests and individuality in the education of his students-a break from Britain's conformist style of education. Seeking innovation from conven- tion is the lesson from history that strikes to the core of the Wilderness Medicine Society.

For the past 27 years, the WMS has been built on the ingenuity, creativity, and determination of our members. As we consider the future of the WMS, the education of George Mallory reminds us that we not only strive to be a society for collaboration and establishment of standards of care, but also-perhaps most importantly-we as a society look to provide inspiration, mentorship, and education to the next generation of intrepid explorers in the world of wilderness medicine. (Figures 1-2).

\section{References}

1. Irving RLG. The Romance of Mountaineering. London, England: J. M. Dent; 1935.

2. Hemmleb J, Johnson L, Simonson E. Ghosts of Everest: The Search for Mallory and Irvine. Seattle, WA: Mountaineers Books; 1999:121-129.

3. Gillman P, Gillman L. The Wildest Dream: The Biography of George Mallory. Seattle, WA: The Mountaineers Books; 2000. 